\title{
Tube Thoracostomy Complications: More to Learn
}

\author{
Affirul Chairil Ariffin ${ }^{1}$
}

Published online: 25 July 2017

(c) Société Internationale de Chirurgie 2017

I read with great interest the article written by Hernandez et al. [1] with regard to the high cost related to tube thoracostomy complication. Although cost is the main theme in this article, it does raise few questions with regard to the complications.

Personally, we do come across this problem occasionally but not so often. The data showed a $37 \%$ cases with complications which mostly are related to technical problem. I do agree that these complications come with a higher cost, but the amount of these complications is somewhat worrying. Though the highest complication rate in trauma patients is $36 \%$, data from the recent millennium suggest the range between 3 and $8-10 \%$ [2].

In the analysis of the data, only the interspace of ribs was included. Though it is one of the main ones, other major factors could contribute. The level of experience of the operators during insertion could be a factor. Kashani et al. [3] showed a $60 \%$ complication rate when performed by residents. An analysis of the knowledge, attitude and practice (KAP) of operators would shed some light on this matter. The technique used for insertion between 'blind' versus open method could be associated with the high complication [4]. Tube thoracostomy size is another common factor although it is debatable in most of the literature. An article even suggested the location of insertion matters whereby tube thoracostomy insertion in the ward has more complications then insertion in emergency departments [5].

Being a retrospective study, it would be challenging to obtain the appropriate data with regard to these factors to be included in the analysis. But I do believe it is worthwhile considering especially with a high complication rate such as this. I would be interested to know whether these factors play a significant role in such a high complication rate and aid other clinicians in preventing it.

\section{References}

1. Hernandez MC, Zeb MH, Heller SF et al (2017) Tube thoracostomy complications increase cost. World J Surg 41:1482-1487. doi:10.1007/s00268-017-3897-7

2. Osinowo O, Softah AL, Eid ZM (2002) Ectopic chest tube insertions: diagnosis and strategies for prevention. Afr J Med Med Sci 31:67-70

3. Kashani P, Harati S, Shirafkan A et al (2017) Comparing the quality and complications of tube thoracostomy by emergency medicine and surgery residents; a cohort study. Emergency 5:e33

4. John M, Razi S, Sainathan S et al (2014) Is the trocar technique for tube thoracostomy safe in the current era? Interact Cardiovasc Thorac Surg 19:125-128

5. Chan L, Reilly KM, Henderson C et al (1997) Complication rates of tube thoracostomy. Am J Emerg Med 15:368-370

Affirul Chairil Ariffin

mraffirul@gmail.com

1 Medical Faculty, Universiti Sains Islam Malaysia (USIM), 55100 Kuala Lumpur, Malaysia 